\title{
Pea Seedling Amine Oxidase Application: an Emerging Antihistamine Strategy in Tuna Fish
}

Hadi Ebrahimnejad, Hamidreza Gheisari* and Abdollah Hossein Khan Nazer

Food Hygiene Department, School of Veterinary Medicine, Shiraz University, Shiraz-Iran

\begin{abstract}
Despite the known antihistaminic effects of PSAO, this enzyme remains unrecognized as an antihistamine additive in the food industry. The objective of this study was to ascertain the plausible histamine-degrading effects of a new food-grade additive (pea seedling extract) in tuna fish. PSAO was purified from cultured pea seedlings via ionexchange and size-exclusion chromatography. SDS-PAGE results indicated that the PSAO subunit has an apparent molecular weight of about $95 \mathrm{kDa}$. To evaluate the optimized conditions for antihistaminic activity of the enzyme, the reaction of PSAO and histamine was carried out in KPi buffer under conditions relevant to the fish processing industry. 1 unit $\mathrm{mL}^{-1}$ of PSAO significantly reduced the histamine content at $\mathrm{pH} 7.0$ but not at $\mathrm{pH} 5.0$. Accordingly, its antihistaminic activity was assessed in homogenized skipjack tuna fish (Katsuwonus pelamis) using an ion-paired HPLC method. The results showed that PSAO can reduce $87.14 \%$ of the histamine content of the tuna fish at $\mathrm{pH} 7.0$, $37^{\circ} \mathrm{C}$. This study indicates that PSAO - purified or even filtrate of pea seedling homogenate - can degrade histamine, which suggests practical application of this enzyme in fish processing industry.
\end{abstract}

Keywords: Pea seedling Amine oxidase (PSAO); Antihistamine activity; Tuna fish

\section{Introduction}

Histamine can only be synthesized by the decarboxylation of L-histidine via L-histidine decarboxylase (HDC) (E.C. 4.1.1.22). In addition, histamine seems to be the toxic component of scombrotoxin, which causes scombroid poisoning. This allergy-like foodborne disease is mostly associated with the consumption of fish, particularly of the Scombridae and Scomberesocidae families [1].

Preventative measures, such as the proper onboard handling of fish and an unbroken cold chain, will reduce the risk of scombroid poisoning. Histamine is a thermostable compound: once the synthesis occurs via improper onboard handling or a broken cold chain, it cannot be degraded by industrial thermal processes [2]. Despite the reported levels of histamine in (processed) fish, outbreaks of scombroid poisoning - often underreported - continue to occur [3-5]. Since there is no industrial process of histamine degradation, these measures remain the only method of reducing histamine level in fish and preventing outbreaks of scombroid poisoning.

Diamine oxidases (DAOs), a group of amine oxidases, prefer to metabolize the biogenic amines such as putrescine, cadaverine and histamine. In the body, DAO is the main enzyme for the metabolism of ingested histamine; Moreover, DAO of plant origin was proposed for the general treatment of histamine-related pathologic conditions [6-8].

Intriguingly, pea seedling amine oxidase (PSAO), a coppercontaining diamine oxidase, catalyzes the oxidative deamination of histamine to the corresponding aldehyde i.e. imidazole acetaldehydeconcomitant with the reduction of dioxygen to hydrogen peroxide $[9,10]:$

Hidysminr $+\mathrm{O}_{2}+\mathrm{H}_{2} \mathrm{O} \stackrel{\text { PSAO }}{\longrightarrow}$ Imidazole acetaldehyde $+\mathrm{NH}_{3}+\mathrm{H}_{2} \mathrm{O}_{2}$

Provided that the histamine-reducing effect of PSAO also applies to seafood and histamine-rich fermented foods, PSAO could offer a natural additive to the corresponding food industries. The objective of the present work was to evaluate the potential impact of PSAO on the oxidative degradation of histamine generated in tuna fish.

\section{Materials and Methods}

\section{Preparation of plant materials}

Pea seeds (Pisum sativum $\mathrm{L}$ ) were purchased from Nunhems Zaden $B V$, Haelen, Netherlands. The seeds, disinfected with a solution of sodium hypochlorite, were cultured in plastic plug-trays with a soilless media of cocopeat and perlite $(1: 1 \mathrm{v} / \mathrm{v})$. The etiolated (dark-grown) seedlings were harvested above the roots after 12-days germination at room temperature. After harvesting, immediate purification of PSAO was carried out at $4^{\circ} \mathrm{C}$.

\section{PSAO purification}

PSAO was purified by modifying a published procedure [11]. The slick slurry of pea seedling homogenate was made with 2 volume of potassium phosphate buffer (KPi buffer) $(0.1 \mathrm{M}, \mathrm{pH} 7.0)$ in an UltraTurrax $^{\oplus}$ (T50 basic, Germany) blender (10,000 rpm) for 10 minutes. The homogenate was filtered through four layers of cheese cloth, and the resulting filtrate was centrifuged at 27,000 $\mathrm{g}$ (F-28/50 rotor of RC-5 Superspeed Refrigerated Centrifuge, Sorvall) for $30 \mathrm{~min}$ at $4^{\circ} \mathrm{C}$. The supernatant was brought to $30 \%$ saturation in ammonium sulphate solution. After a second centrifugation at $27,000 \mathrm{~g}$ for $20 \mathrm{~min}$, the supernatant was further fractioned with ammonium sulphate in $70 \%$ saturation. The precipitate was then separated by centrifugation at $27,000 \mathrm{~g}$ for $20 \mathrm{~min}$, resuspended in $20 \mathrm{~mL}$ of $\mathrm{KPi}$ buffer $(0.1 \mathrm{M}$, $\mathrm{pH}$ 7.0), and dialyzed against the same buffer overnight (D6066, Sigma-Aldrich). The dialyzed solution was stored at $-18^{\circ} \mathrm{C}$ and used as a crude extract. This dialyzed solution was then applied onto a

*Corresponding author: Hamidreza Gheisari, Food Hygiene Department, Schoo of Veterinary Medicine, Shiraz University, Shiraz-Iran, E-mail: ghaisari@shirazu.ac.ir Received April 06, 2013; Accepted June 03, 2013; Published June 10, 2013

Citation: Ebrahimnejad H, Gheisari H, Khan Nazer AH (2013) Pea Seedling Amine Oxidase Application: an Emerging Antihistamine Strategy in Tuna Fish. J Food Process Technol 4: 242. doi:10.4172/2157-7110.1000242

Copyright: (c) 2013 Ebrahimnejad H, et al. This is an open-access article distributed under the terms of the Creative Commons Attribution License, which permits unrestricted use, distribution, and reproduction in any medium, provided the original author and source are credited. 
diethylaminoethyl (DEAE) cellulose column $(\varnothing=2.5 \mathrm{~cm}, l=20 \mathrm{~cm})$ (D3764, Sigma-Aldrich) and washed with KPi buffer (0.02 M, pH 7.0) at a flow rate of $15 \mathrm{~mL} / \mathrm{h}$. The elution was performed by KPi buffer $(0.1$ $\mathrm{M}, \mathrm{pH}$ 7.0) containing $0.1 \mathrm{M} \mathrm{KCl}$ at a flow rate of $15 \mathrm{~mL} / \mathrm{h}$. Fractions showing enzymatic activity-tubes 9-21-were pooled and lyophilized to $3 \mathrm{~mL}$ volume and then loaded onto a column of Sephadex G-200 superfine $(\varnothing=1.5 \mathrm{~cm}, l=53 \mathrm{~cm})$ (84961, Sigma-Aldrich). The sample was washed with KPi buffer $(0.02 \mathrm{M}, \mathrm{pH} 7.0)$ at a flow rate of $15 \mathrm{~mL} / \mathrm{h}$. Once again active fractions were pooled and lyophilized.

Enzyme assay: An established spectrophotometric assay-as described by Kluetz et al. [12] was used to evaluate the activity of PSAO. The enzyme was applied to benzylamine substrate, and the increase in absorbance, due to the benzaldehyde formation, was monitored on a Gilford Model $252 \mathrm{UV}$-vis spectrophotometer for at least $10 \mathrm{~min}$. One unit of enzymatic activity is defined as the amount that catalyzes the conversion of $1 \mu$ mole of substrate to product per minute at $37^{\circ} \mathrm{C}$.

Total protein assay: The total protein amount was determined spectrophotometrically using both the Lowry and Bradford methods.

SDS-PAGEanalysis: SDS-PAGE was performed on a discontinuous gel system with two sequential gels $(10 \% \mathrm{~T}, 2.5 \% \mathrm{C})$. The samples $(2$ mg. $\mathrm{mL}^{-1}$ ) dissolved in a sample buffer and boiled at $100^{\circ} \mathrm{C}$ for $10 \mathrm{~min}$ before the application on gel. The gels were stained with Coomassie Brilliant Blue G-250 while PageRuler ${ }^{\mathrm{Ta}}$ Plus Prestained Protein Ladder (SM1811, Fermentas) was used as a protein molecular weight marker.

\section{HPLC evaluation of histamine}

Histamine detection by high performance liquid chromatography (HPLC) was performed as described previously [13], in which procedure had no laborious pre-treatment, clean up and derivatization. All of the HPLC evaluations were done in triplicate.

HPLC chemicals: HPLC-grade methanol (34869) and acetonitrile (34998), histamine dihydrochloride (H7250), 1,1-dimethylbiguanide hydrochloride (D150959) and 1-decanesulfonic acid sodium salt (30633) were supplied by Sigma-Aldrich (Munich, Germany). Analytical grade reagents $\left(\mathrm{KH}_{2} \mathrm{PO}_{4}, \mathrm{~K}_{2} \mathrm{HPO}_{4} \cdot 3 \mathrm{H}_{2} \mathrm{O}\right.$ and $\left.\mathrm{HClO}_{4}\right)$ were supplied by Merck (Darmstadt, Germany). The water used was obtained using the Milli-Q purification system of Millipore.

HPLC solutions and eluents: The 1000 ppm stock solutions of 1,1-dimethylbiguanide hydrochloride and histamine dihydrochloride prepared by dissolving them in $\mathrm{HCl}(0.1 \mathrm{M})$. The histamine working solutions at a concentration of $2-5-8-10-15-30-50 \mathrm{mg} / \mathrm{l}$ in $\mathrm{HCl}$ $(0.1 \mathrm{M})$ were prepared fresh every day. The final concentration of 1,1-dimethylbiguanide hydrochloride (chromatographic reference standard) which added to all the solutions was about $5 \mathrm{mg} \mathrm{L}^{-1}$. Solution of $\mathrm{HClO}_{4}(1 \mathrm{M})$ was used as an extraction solvent of histamine from fish. A mobile phase of buffer solution: methanol: acetonitrile (75:10:15, $\mathrm{v} / \mathrm{v} / \mathrm{v}$ ) was delivered at a flow rate of $1.0 \mathrm{mLmin}^{-1}$ to the column. The buffer solution, $1.72 \mathrm{~g}$ of $\mathrm{KH}_{2} \mathrm{PO}_{4}, 2.7 \mathrm{~g}$ of $\mathrm{K}_{2} \mathrm{HPO}_{4} \cdot 3 \mathrm{H}_{2} \mathrm{O}$ and $0.49 \mathrm{~g}$ of $\mathrm{C}_{10} \mathrm{H}_{21} \mathrm{O}_{3} \mathrm{SNa}$ (sodium 1-decanesulfonate) in $1 \mathrm{~L}$ water with a final $\mathrm{pH}$ of 6.7, was filtrated through a $0.45-\mu \mathrm{m}$ Millipore membrane filter, and degased before use in an ultrasonic bath (Sonorex Super RK 100/H). The buffer solution was prepared at the time of use.

HPLC equipment and conditions: The HPLC analyses were carried out using an Agilent HPLC system (Agilent 1100 series, Waldbronn, Germany) equipped with a quat pump G1311A, autosampler G1313A, variable wavelength detector (VWD) G1314A and degasser G1379A. The separations were performed under isocratic conditions using a 5 $\mu \mathrm{m} \mathrm{C18}$ column of $250 \mathrm{~mm} \times 4.6 \mathrm{~mm}$ i.d. (Spherical, Optimal ${ }^{\circ} \mathrm{ODS}-\mathrm{H}$, Capital HPLC, UK) fitted with a $5 \mu \mathrm{m} \mathrm{C18}$ guard column of $20 \mathrm{~mm} \times 4.6$ $\mathrm{mm}$ (Spherical, Optimal ${ }^{\circ}$ ODS-H, Capital HPLC, UK). The flow rate was $1.0 \mathrm{mLmin}^{-1}$, the injection volume $30 \mu \mathrm{L}$ and the VWD was positioned at a wavelength of $214 \mathrm{~nm}$.

\section{In vitro optimization of antihistamine activity of PSAO}

The antihistamine activity of 1 unit $\mathrm{mL}^{-1}$ SEC-PSAO (Size-exclusion chromatography pool of PSAO) has been evaluated upon the substrate of histamine dihydrochloride with KPi buffers $(0.02 \mathrm{M}$; pH 5.0 and $\mathrm{pH}$ 7.0) at two temperatures $\left(25^{\circ} \mathrm{C}\right.$ and $\left.37^{\circ} \mathrm{C}\right)$ within three time periods $(0$ 30 and 60 minutes). Application of KPi buffer instead of the enzyme was used as control and the HPLC without any histamine-extraction procedure was performed for the evaluation of antihistamine activity of PSAO.

\section{Evaluation of antihistamine effect of PSAO in tuna fish}

Histamine production of an onboard-frozen skipjack tuna fish with negligible amount of histamine - was enhanced by incubation at the optimum temperature of histamine formation in skipjack tuna fish $\left(37^{\circ} \mathrm{C}, 24 \mathrm{~h}\right)$ [14]. The initial histamine level was spotted after the incubation (F1). Thereafter, to obtain at least 50\% histamine degradation; tuna fish experimental groups encompass: control plain fish (F2), and the rest comprise tuna fish associated with $4 \mu \mathrm{molg}^{-1}$ pyridoxal 5'-phosphate (P9255, Sigma-Aldrich, Munich, Germany) (F3), 4 unit $\mathrm{mL}^{-1}$ SEC-PSAO (F4), 4 unitmL $^{-1}$ filtrate of pea seedling homogenate (F5), 4 unitmL $^{-1}$ filtrate of pea seedling homogenate plus $4 \mu \mathrm{mol} \mathrm{g} \mathrm{g}^{-1}$ pyridoxal $5^{\prime}$-phosphate (F6) were hygienically provided from the homogenized (Ultra-Turrax T25D, Germany; $1000 \mathrm{rpm}, 3$ min) anterio-dorsal fish meat. The treatments (F2 - F6) were incubated $\left(37^{\circ} \mathrm{C}, 30 \mathrm{~min}\right)$ providing optimum enzymatic situation, while thenceforth PSAO was inactivated through high temperature $\left(100^{\circ} \mathrm{C}\right.$ $10 \mathrm{~min}$ ). Afterwards, histamine extraction of previously homogenized tuna fish was performed by weighing out 5 grams of each experiment into a centrifuge test tube and $250 \mu \mathrm{L}$ of the chromatographic reference standard (1,1-dimethylbiguanide hydrochloride) added so as to obtain a concentration of about $5 \mathrm{mg} \mathrm{L}^{-1}$ and allowed to stand at room temperature for 30 minutes. $20 \mathrm{~mL}$ of $\mathrm{HClO}_{4}(1 \mathrm{M})$ was then added to the test tube; the mixture was homogenized at $1000 \mathrm{rpm}$ for $3 \mathrm{~min}$ and then centrifuged at $+4^{\circ} \mathrm{C}(4200 \mathrm{rpm}, 15 \mathrm{~min})$, the supernatant was filtered through a Whatman filter into a $50 \mathrm{~mL}$ flask. This procedure was repeated twice. The combined extracts brought up to volume with distilled water, filtered through a PTFE $(0.45 \mu \mathrm{m})$ and injected into the HPLC-VWD system.

\section{Statistical analysis}

Values in all experiments are represented as mean \pm SD of experiments done in triplicate. The decrease in histamine content due to the PSAO activity - was considered significant at $\mathrm{p}<0.05$ using One-Way ANOVA, followed by the Duncan's post-hoc test. (Statistical package SPSS version 16.0)

\section{Results and Discussions}

\section{PSAO purification}

It has been hypothesized that the PSAO activity - per gram of pea seedling tissue - is proportional to the growth rate and conditions. In general, etiolated seedlings have higher DAO levels as compared to those detected in light-grown seedlings. The 12-day-old etiolated seedlings had the highest PSAO-specific activity $[12,15]$. Purification 
scheme of PSAO is demonstrated in Table 1. The measured quantities listed were obtained following the stated step in the procedure.

Figure 1 shows the results of purification of PSAO from 12-day-old etiolated pea seedlings. Several peaks were obtained from the DEAEcellulose column; however, the fractions showing enzymatic activity were pooled. In this purification procedure, almost no contamination with other proteins was detectable after performing chromatography upon Coo-massive Brilliant Blue staining of the electrophoresis gel.

Electrophoresis of partially purified PSAO on SDS-PAGE showed a single band. Upon comparing the band's mobility of DAO to those of known molecular weight standard proteins on $10 \%$ gels, we determined the subunit molecular weight of DAO to be about $95 \mathrm{kDa}$ (Figure 2). Kluetz et al. [12] found similar properties for the PSAO and also illustrated that, when these two subunits were cross-linked with dimethylsuberimidate, a new band could appear with a molecular weight of approximately $178 \mathrm{kDa}$, which suggests that the native enzyme consists of two apparently-identical subunits.

\section{HPLC analysis and quantification of histamine}

Histamine is not stable in water; but well-stable in acidic conditions. Based on this rationale, acidic histamine extraction of fish samples in $\mathrm{HClO}_{4}$ provides a good chromatographic peak resolution [13].

The ion-pairing HPLC with sodium 1-decanesulfonate as an ion pairing reagent was performed while the anionic sulfonate counterion, which permits the separation and resolution of positively charged analytes such as histamine [16]. In this specific method of histamine quantification in fish, the differences between the retention/migration times has been reduced to $\pm 1 \%$ by applying the chromatographic reference standard of 1,1-dimethylbiguanide, a basic compound with characteristics similar to histamine [13]. Before histamine measurement, seven histamine standards generate the calibration curves while the correlation coefficient exceeded 0.999. Histamine peak in samples was recognized and quantified by comparing its retention time to the chromatographic reference peak and also to histamine standards. Under the HPLC conditions adopted, the analytes were fully separated in $10 \mathrm{~min}$ (Figure 3 ).

\section{Optimization of antihistamine activity of PSAO}

To obtain a deeper insight into PSAO potential for histamine degradation in tuna fish, its antihistaminic effect was investigated in a buffered system, prior to application in fish, through an HPLC experiment. According to Huss et al. [17], $\mathrm{pH}$ value in most of the processed fish (e.g: lightly preserved, fermented, semi-preserved and heat-processed) is between acidic and neutral; hence, the antihistamine activity of PSAO was evaluated at $\mathrm{pH}=5$ and $\mathrm{pH}=7$ of $\mathrm{KPi}$ buffer system. Two temperatures were tested for the antihistamine activity of the enzyme: $37^{\circ} \mathrm{C}$, the optimum temperature of porcine diamine

\begin{tabular}{|c|c|c|c|}
\hline \multirow{2}{*}{ Step } & Total Activity & Specific Activity & Yield \\
\hline & units & units/mg & $\%$ \\
\hline filtrate of pea seedling homogenate & 28204.22 & 1.08 & 100 \\
\hline $30 \%$ A.S. ${ }^{1}$ fractionation & 25941.98 & 1.23 & 92 \\
\hline $70 \%$ A.S. fractionation & 23173.61 & 3.62 & 82.3 \\
\hline DEAE-cellulose chromatography & 14638.97 & 4.07 & 52 \\
\hline Sephadex G-200 chromatography & 13143.66 & 8.85 & 46.6 \\
\hline \multicolumn{4}{|c|}{ 1: ammonium sulfate } \\
\hline
\end{tabular}

Table 1: Purification steps of PSAO. The data have been normalized to a starting value of $1 \mathrm{~kg}$ of plant tissue.

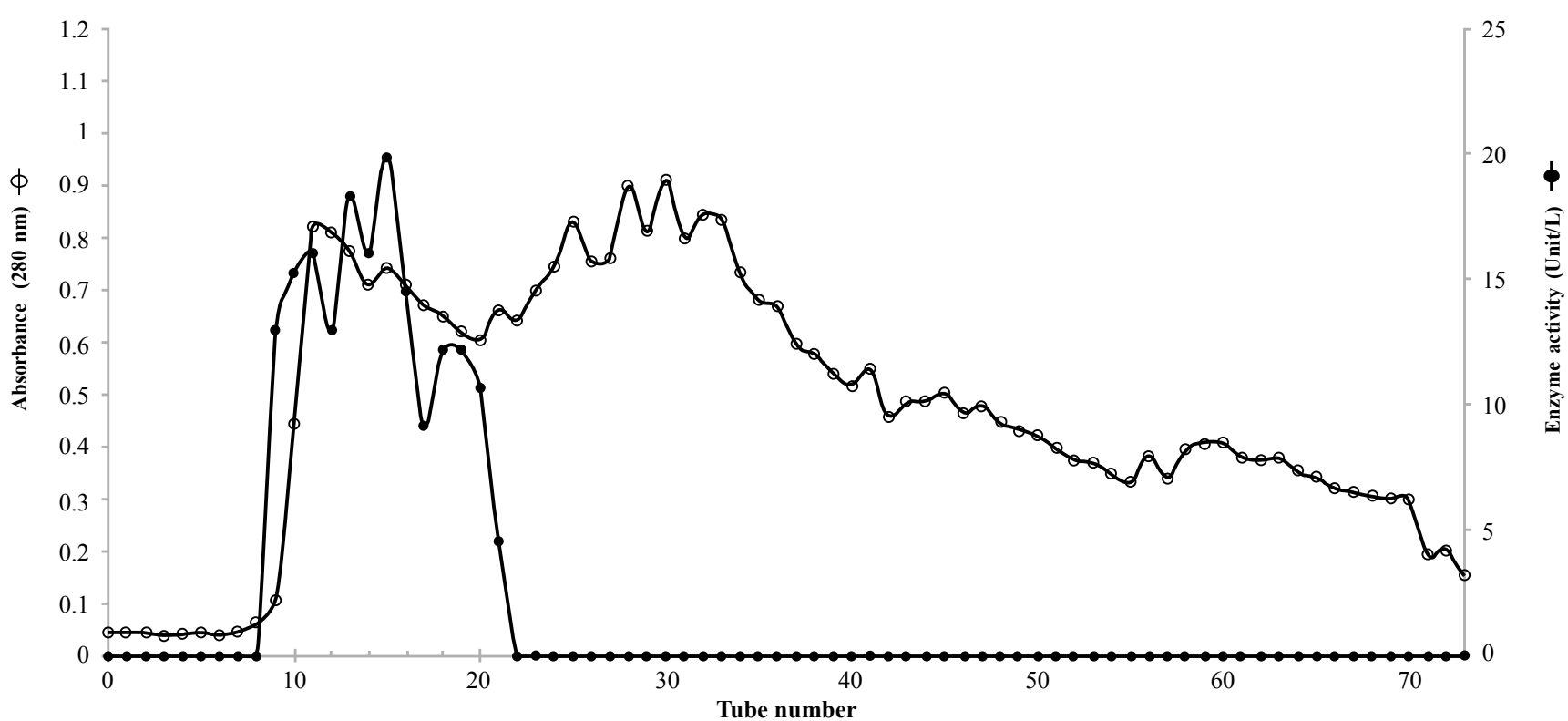

Figure 1: DEAE-cellulose chromatography for purification of PSAO. 5 milliliters solution containing $30 \mathrm{mgmL}^{-1}$ protein was applied to a DEAE-cellulose column $(\varnothing=$ $2.5 \mathrm{~cm}, I=20 \mathrm{~cm})$ equilibrated with KPi buffer $(0.02 \mathrm{M}, \mathrm{pH} 7.0)$ at a flow rate of $15 \mathrm{~mL} / \mathrm{h}$. Arrow indicates start of elution by KPi buffer $(0.1 \mathrm{M}$, pH 7.0$)$ containing 0.1 $\mathrm{M} \mathrm{KCl} 3$ milliliters were collected in each tube. Active fractions - tubes 9-21 - were pooled and lyophilized. 


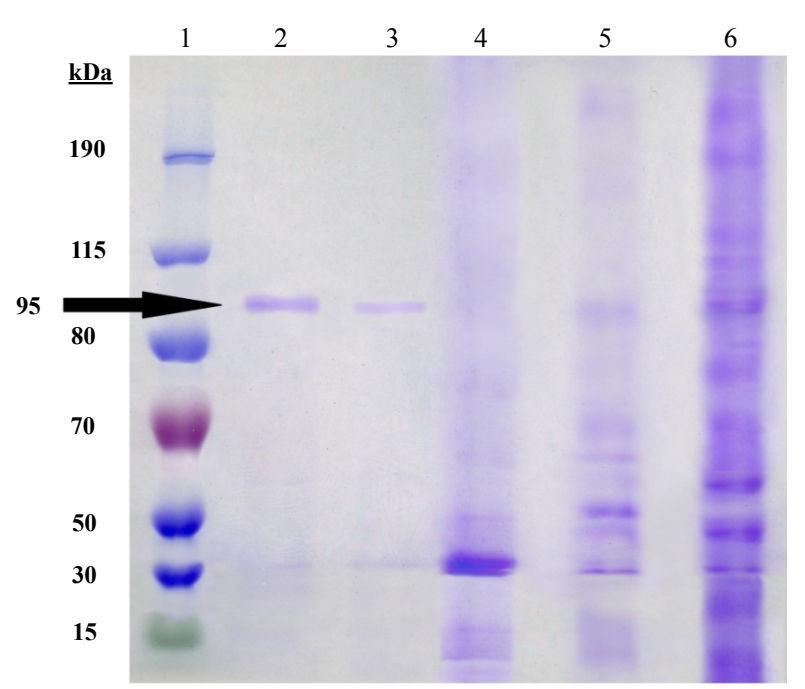

Figure 2: Electrophoretic analysis of PSAO on different stages of its purification. Proteins (2 $\left.\mathrm{mg} \mathrm{mL}^{-1}\right)$ at each purification step were resolved by SDS-PAGE and stained with Coomassie Brilliant Blue. Line 1: molecular mass markers, lane 2: Sephadex G-200 chromatography, line 3: DEAE-cellulose chromatography, line 4: 70\% ammonium sulfate fractionation, line 5: $30 \%$ ammonium sulfate fractionation and line 6: filtrate of pea seedling homogenate.

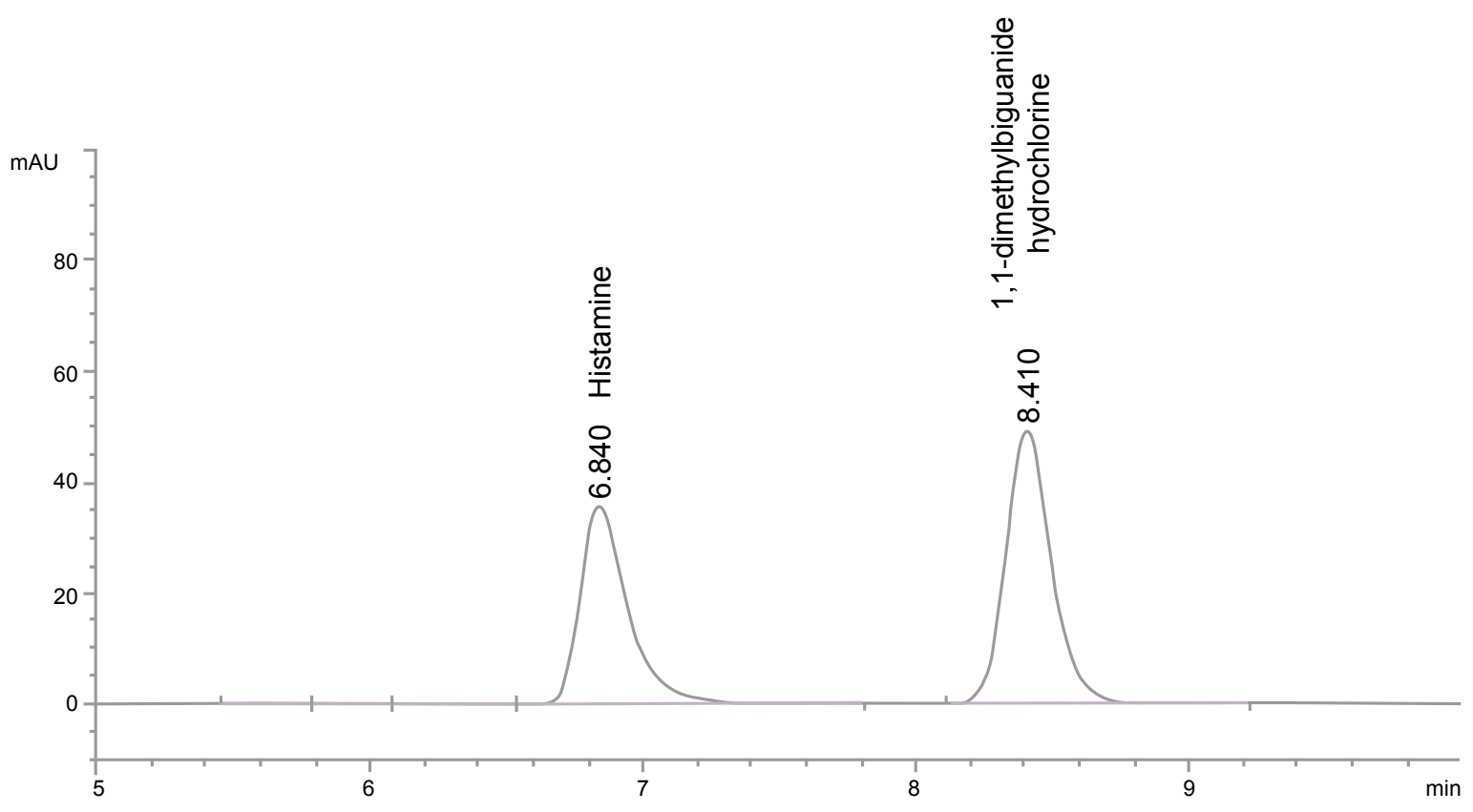

Figure 3: HPLC chromatogram of histamine (200 ppm) and 1,1-dimethylbiguanide standard in KPi buffer (pH 7.0, $\left.37^{\circ} \mathrm{C}\right)$; conditions: column Optimal ODS-H C18 (250 mm $\times 4.6 \mathrm{~mm}$ i.d.) at $+35^{\circ} \mathrm{C}$, buffer solution: methanol: acetonitrile $(75: 10: 15, \mathrm{v} / \mathrm{v} / \mathrm{v})$ at a flow-rate of $1.0 \mathrm{~mL}^{\mathrm{min}}{ }^{-1}$, injection loop $30 \mu \mathrm{L}$ and monitored at $214 \mathrm{~nm}$.

oxidase according to Dapkevicius et al. [18]; and $25^{\circ} \mathrm{C}$, since the probable application of the enzyme in fish processing industry might occur at room temperature. Antihistamine activity was determined by measuring the decrease in histamine concentration of KPi buffer (Figure 4).

In contrast to the control group, PSAO could not reduce histamine content of $\mathrm{KPi}$ buffer system in $\mathrm{pH} 5.0$ (in neither $25^{\circ} \mathrm{C}$ nor $\left.37^{\circ} \mathrm{C}\right)(\mathrm{One}-$ Way ANOVA; $p<0.05)$. Possible causes include the histamine charge alteration in $\mathrm{pH} 5.0$ [19] resulting in improper attachment of histamine into the enzyme active site, the withdrawal of the enzyme from its optimum $\mathrm{pH}$ range, and even the feasibility of PSAO denaturation [20].

However, PSAO represented a significant reduction in histamine content of KPi buffer of pH 7.0 after 30 minutes (in either $25^{\circ} \mathrm{C}$ or $37^{\circ} \mathrm{C}$ ) in comparison to control group (One-Way ANOVA; $p<0.05$ ). This is consistent with previous studies $[18,21]$ and suggests that this $\mathrm{pH}$ is suitable for PSAO antihistaminic activity.

No significant difference was observed in antihistaminic activity of PSAO between $25^{\circ} \mathrm{C}$ and $37^{\circ} \mathrm{C}$ (One-Way ANOVA, Duncan; $p<0.05$ ). 
Interestingly, whereas no decline of enzyme activity at $25^{\circ} \mathrm{C}$ was observed, it is plausible to apply PSAO in ambient temperature (such as a fish processing environment).

\section{Evaluation of antihistamine effect of PSAO in tuna fish}

The initial histamine level of the onboard-frozen skipjack tuna fish was $3.27 \pm 1.73 \mathrm{ppm}$. Histamine content of the fish was elevated to $16.06 \pm 1.74 \mathrm{ppm}$ after $24 \mathrm{~h}$ at $37^{\circ} \mathrm{C}$.

In spite of the report that porcine diamine oxidase fitted into an exponential decline model of histamine degradation [22], PSAO did not show a significance difference in reduction of histamine in KPi buffer system after 30 or 60 minutes. Regarding food industry condition (and to decrease the risk of food bacterial overload), it is important that the food undergo a minimal holding time before the main thermal process (such as sterilization). Hence, the antihistaminic activity of PSAOwhich can be used before the thermal process in a fish factory - was evaluated after 30 minutes in tuna fish.

The histamine content of the thoroughly homogenized fish increased to $35.72 \pm 7.83 \mathrm{ppm}$ after 30 minutes incubation at $37^{\circ} \mathrm{C}$ (control group). The application of PSAO in homogenized tuna fish $\left(37^{\circ} \mathrm{C}, 30 \mathrm{~min}\right)$ not only prevented the histamine raise - more frequent in the homogenized texture of meat through bacterial action-but also reduced the already existent histamine to the initial level of the skipjack tuna fish frozen onboard (One-Way ANOVA, Duncan; $p<0.05$ ), (Figure 5).

Notably, antihistaminic activity of two steps of enzyme purification (filtrate of pea seedling homogenate and SEC-PSAO steps) was not significantly different (One-Way ANOVA, Duncan; $p<0.05$ ). Accordingly, it is suggested that the filtrate of pea seedling homogenate has the feasibility of histamine reduction in foods.

Although it was concluded that pyridoxal phosphate is a coenzyme for diamine oxidase [23], presently, topaquinone (TPQ) - derived from the modification of a protected tyrosyl residue - has been introduced as the enzyme cofactor [24]. Nonetheless, it has been confirmed that pyridoxal phosphate works as a substrate for peroxidase in pea seedling extracts. Therefore, pyridoxal phosphate does not activate DAO, but prevents the inactivation of the enzyme which might occur by peroxidases $[10,25]$.

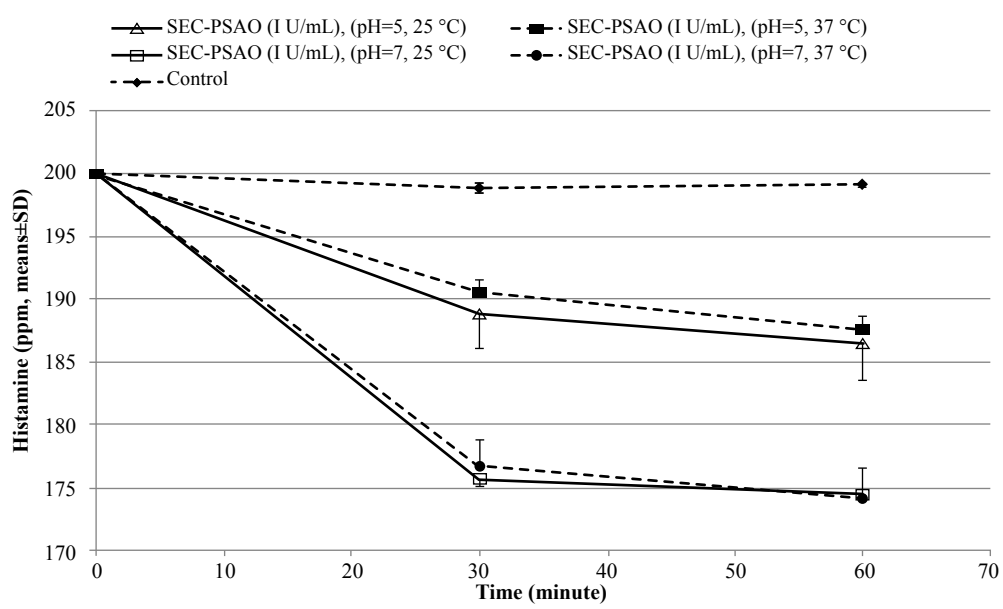

Figure 4: The influence of $\mathrm{pH}$ and temperature of phosphate buffer $(0.02 \mathrm{M})$ on the antihistamine activity of PSAO; the data have been normalized to a starting value of $200 \mathrm{ppm}$.

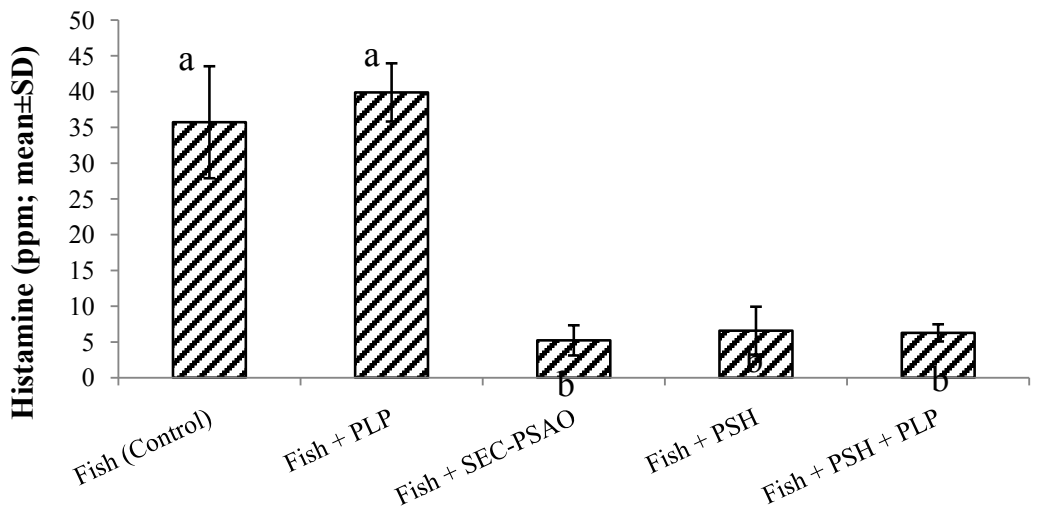

Treatments

Figure 5: Antihistamine activity of PSAO in skipjack tuna fish after 30 minutes at $37{ }^{\circ} \mathrm{C}\left(\mathrm{PLP}\right.$ : pyridoxal 5 -phosphate $\left(4 \mu \mathrm{mol}^{\mathrm{mL}} \mathrm{L}^{-1}\right)$; $\mathrm{SEC}-\mathrm{PSAO}\left(4\right.$ unit $\left.\mathrm{mL}^{-1}\right)$; $\mathrm{PSH}$ : filtrate of pea seedling homogenate $\left(4\right.$ unit $\left.\mathrm{mL}^{-1}\right)$. Different letters indicate a significant difference (Duncan; $\left.p<0.05\right)$. 
In this study, application of pyridoxal phosphate beside the enzyme at $37^{\circ} \mathrm{C}$ did not enhance PSAO activity after 30 minutes, which is consistent with previous studies (One-Way ANOVA, Duncan; $p<0.05$ ); however, pyridoxal phosphate usage resulted in higher histamine content (even if it was not statistically significant) of the tuna fish, which is likely due to its being the cofactor of HDC [26].

\section{Conclusions}

The antihistamine properties assigned to PSAO and the feasibility of efficient enzyme extraction by chromatographic methods, elicits a novel enzymatic strategy for histamine degradation in tuna fish. Accordingly, in this study, 4 unit $\mathrm{mL}^{-1}$ of PSAO reduced $87.14 \%$ of the histamine content of the skipjack tuna fish (Katsuwonus pelamis) at $\mathrm{pH} 7.0,37^{\circ} \mathrm{C}$. Since the filtrate of pea seedling homogenate exerted the same antihistamine results of purified PSAO, its application in fish is more practical because the preparation process is less time and energy consuming. Despite the fruitful results of the study, it seems that the enzyme efficacy can vary due to the diversity and distribution of the enzyme inhibitors regarding the variety of fish species, their environment, and fishing styles [27,28].

\section{Acknowledgment}

This study was supported financially by the Shiraz Univ. Research Council. We would also like to thank $\mathrm{Dr}$ M.J. Khoshnood for his technical advice and cooperation on HPLC analysis.

\section{References}

1. Lawley R, Curtis L, Davis J (2008) The Food Safety Hazard Guidebook. (1 Ed), The Royal Society of Chemistry, Cambridge, UK.

2. FDA (2001) Fish and Fisheries Products Hazards and Controls Guide. ( $3^{\text {rd }}$ Ed), Center for Food Safety and Applied Nutrition, Office of Seafood, Washington DC, USA.

3. Gellert GA, Ralls J, Brown JC, Huston J, Merryman R (1992) Scombroid fish poisoning. Underreporting and prevention among noncommercial recreational fishers. West J Med 157: 645-647.

4. Taylor SL, Stratton JE, Nordlee JA (1989) Histamine poisoning (scombroid fish poisoning): an allergy-like intoxication. J Toxicol Clin Toxicol 27: 225-240.

5. Wu ML, Yang CC, Yang GY, Ger J, Deng JF (1997) Scombroid fish poisoning: an overlooked marine food poisoning. Vet Hum Toxicol 39: 236-241.

6. Jeon HB, Lee Y, Qiao C, Huang H, Sayre LM (2003) Inhibition of bovine plasma amine oxidase by 1,4-diamino-2-butenes and -2-butynes. Bioorgan Med Chem 11: 4631-4641.

7. Mondovi B, Befani O, Federico R, Mateescu MA, Masini E, et al. (2002) A histaminase of Vegetable Origin for Use in the Treatment of Allergic and Septic Shock and of Allergic Asthma. International Patent Publication No: WO/2002/043745.

8. Mondovi B, Rotilio G, Finazzi A, Scioscia-Santoro A (1964) Purification of pigkidney diamine oxidase and its identity with histaminase. Biochem J 91: 408415.

9. Floris G, Mondovì B (2010) Copper Amine Oxidases: Structures, Catalytic Mechanisms, and Role in Pathophysiology. Taylor \& Francis Group, CRC Press, USA.

10. Hill JM (1967) The inactivation of pea-seedling diamine oxidase by peroxidase and 1,5-diaminopentane. Biochem J 104: 1048-1055.

11. Kivirand K, Rinken T (2007) Purification and properties of amine oxidase from pea seedlings. Proc Estonian Acad Sci Chem 56: 1640-171.

12. Kluetz MD, Adamsons K, Flynn JE (1980) Optimized preparation and determination of pea seedling diamine oxidase. Prep Biochem 10: 615-631.
13. Cinquina AL, Longo F, Calì A, Santis LD, Baccelliere R, et al. (2004) Validation and comparison of analytical methods for the determination of histamine in tuna fish samples. J Chromatogr A 1032: 79-85.

14. Frank HA, Yoshinaga DH, Nip WK (1981) Histamine Formation and Honeycombing During Decomposition of Skipjack Tuna, Katsuwonus pelamis, at Elevated Temperatures. Marine Fish Rev 43: 9-14

15. Angelini R, Federico R, Mancinelli A (1988) Phytochrome-Mediated Contro of Diamine Oxidase Level in the Epicotyl of Etiolated Lentil (Lens culinaris Medicus) Seedlings. Plant Physiol 88: 1207-1209.

16. Hancock WS, Bishop CA, Meyer LJ, Harding DRK, Hearn MTW (1978) Highpressure liquid chromatography of peptides and proteins: VI. Rapid analysis of peptides by high-pressure liquid chromatography with hydrophobic ion-pairing of amino groups. J Chromatogr A 161: 291-298.

17. Huss HH, Ababouch L, Gram L (2004) Assessment and management of seafood safety and quality. FAO, Rome.

18. Dapkevicius MLNE, Nout MJR, Rombouts FM, Houben JH, Wymenga W (2013) Biogenic amine formation and degradation by potential fish silage starter microorganisms. Int J Food Microbiol 57: 107-114.

19. Maśliński C (1975) Histamine and its metabolism in mammals. Part I: Chemistry and formation of histamine. Agents Actions 5: 89-107.

20. Mondovì B, Rotilio G, Costa MT, Finazzi-Agrò A, Chiancone E, et al. (1967) Diamine oxidase from pig kidney. Improved purification and properties. J Biol Chem 242: 1160-1167.

21. Naila A, Flint S, Fletcher GC, Bremer PJ, Meerdink G (2012) Histamine Degradation by Diamine Oxidase, Lactobacillus and Vergibacillus halodonitrificans Nai18. J Food Process Technol 3: 158.

22. Naila A, Flint S, Fletcher GC, Bremer PJ, Meerdink G, et al. (2012) Prediction of the amount and rate of histamine degradation by diamine oxidase (DAO). Food Chem 135: 2650-2660.

23. Davison AN (1956) Pyridoxal phosphate as coenzyme of diamine oxidase Biochem J 64: 546-548.

24. Shepard EM, Juda GA, Ling KQ, Sayre LM, Dooley DM (2004) Cyanide as a copper and quinone-directed inhibitor of amine oxidases from pea seedlings ( Pisum sativum) and Arthrobacter globiformis: evidence for both coppe coordination and cyanohydrin derivatization of the quinone cofactor. $\mathrm{J}$ Biol Inorg Chem 9: 256-268.

25. Hill JM (1970) The oxidation of pyridoxal and related compounds by peaseedling extracts or systems containing peroxidase. Phytochem 9: 725-734.

26. Guirard BM, Snell EE (1954) Pyridoxal Phosphate and Metal lons as Cofactors for Histidine Decarboxylase. J Am Chem Soc 76: 4745-4746.

27. Longu S, Mura A, Padiglia A, Medda R, Floris G (2005) Mechanism-based inactivators of plant copper/quinone containing amine oxidases. Phytochemistry 66: $1751-1758$.

28. Stránská J, Sebela M, Tarkowski $P$, Rehulka $P$, Chmelík J, et al. (2007) Inhibition of plant amine oxidases by a novel series of diamine derivatives. Biochimie 89: 135-144. 